\title{
Beyond returns: Investigating the Social and Environmental Impact of Sustainable Investing
}

\author{
Julian F. Kölbel ${ }^{1,2}$, Florian Heeb², Falko Paetzold ${ }^{2}$, Timo Busch ${ }^{2,3}$ \\ ${ }^{1}$ MIT Sloan, Cambridge MA, USA \\ ${ }^{2}$ University of Zurich, Department of Banking and Finance, Center for Sustainable \\ Finance and Private Wealth (CSP), Plattenstrasse 32, 8032 Zürich, Switzerland \\ ${ }^{3}$ University of Hamburg, School of Business, Economics and Social Science, \\ Von-Melle-Park 9, 20146 Hamburg, Germany
}

This version: November 2018

\begin{abstract}
While many studies have examined the financial performance of sustainable investing (SI), little is known about the social and environmental impact of SI. We address this research gap in a multi-disciplinary literature review. We begin by developing a definition of investment impact, and a framework that clarifies the relationship between an investor's impact on a company and a company's impact on the real world. Focusing on investor impact, the literature review brings together evidence on three mechanisms: shareholder engagement impact, capital allocation impact, and indirect impacts. We find direct evidence that investors can affect companies through shareholder engagement, especially when the costs of demanded reforms are low, investors wield influence, and companies have prior experience with engagement. We find only indirect evidence for the capital allocation impact, yet studies indicate that this impact is more likely when SI investors hold a large market share, deviate strongly from the market portfolio, and focus on assets that are hard to substitute. The capital allocation impact is also more likely when companies depend on external financing for growth, and when the cost of conforming with the expectations of SI investors is low. Indirect effects, where investors rely on intermediaries to influence companies, have little support in the literature. Our results suggest that investors can increase their impact by expanding engagement efforts, by focusing on widely shared priority issues, making sure these issues are assessed consistently, and by targeting markets where external capital is a limiting factor.
\end{abstract}

\author{
JEL Classification: A13, G11, G12, Q51, Q56 \\ Keywords: Sustainable Investment; Impact; Causality; Literature Review; Sustainability
}

\section{Acknowledgments:}

We gratefully acknowledge financial support from the Luc Hoffman Institute. We thank James Gifford, Jonathan Krakow, Vincent Wolf, Alex Barkawi, Britta Rendlen, Emilio Marti, Raj Thamoteram, Tillmann Lang, Julia Meyer, David Wood, and Florian Berg for valuable input and discussions. We would also like to thank participants of the Luc Hoffmann Institute workshop "Shareholder Activism for Sustainability" on May 28, 2018, and of the Yale Initiative on Sustainable Finance Symposium 2018. 


\section{Introduction}

Sustainable investing (SI) was originally devised as a tool to improve the world. Historically, when it was still called 'responsible investing', the Quakers divested from businesses associated with slavery, and colleges divested from companies to protest the South African apartheid regime (Molthan, 2003). Also today, many investors are attracted to SI by altruistic motives (Hartzmark and Sussman, 2017; Riedl and Smeets, 2017), expecting that SI will allow them to make a positive contribution. In line with this desire from investors, policymakers discuss SI as a mechanism to help realize the UN's sustainable development goals (Betti, Consolandi, and Eccles, 2018), as well as to hold back climate change (IPCC, 2014).

Over the last decades, the SI industry has increasingly adopted the so-called 'business case', which emphasizes the financial performance of SI, rather than its social and environmental contributions (Richardson, 2009). SI has also grown rapidly over the last decades; some studies estimate that one in four dollars globally is in SI (GSIA, 2016). Academic research on SI has overwhelmingly embraced the logic of the business case. Over 2000 studies examine the financial outcomes of SI (Friede, Busch, and Bassen, 2015), yet only a few studies investigate the environmental and social outcomes of SI (see e.g. Rivoli, 2003).

This results in a problematic research gap: while SI is assumed to be a tool to improve the world, its impact on environmental and social outcomes is unclear. It is unknown, for instance, whether the enormous growth of SI has contributed in a meaningful way to a reduction of global greenhouse gas emissions. This knowledge gap has an important ethical dimension because important goals ought to be pursued with effective means (Singer, 2015). SI has both the potential to greatly facilitate the achievement of global development goals, as well as to divert substantial human and financial resources from other, more effective means. Thus, before investors and policymakers rely on SI as a means to address some of the world's greatest challenges, there is an urgent need to investigate the impact of SI.

An important reason for the existence of this research gap is that the issue of investment impact cuts across disparate disciplines. Relevant studies can be found in financial economics (Hong and Kacperczyk, 2009), business ethics (Rivoli, 2003), legal

scholarship (Richardson, 2009), and industrial ecology (Koellner et al., 2008). At this point, 
there is no scholarship that investigates investment impact holistically and brings together the existing evidence that is available on the topic of investment impact.

This review article takes stock of what is currently known about the investment impact of SI. First, we provide a definition and a framework for investment impact, in order to clarify the concept and to set the scope of the literature review. We highlight that investment impact consists of two complementary components, namely investor impact - the impact of investors on companies and company impact - the impact of companies on the outcomes that are ultimately desired (Brest and Born, 2013). Focusing on investor impact, we identify mechanisms through which investor impact can be achieved and review a wide range of literature that deals with these mechanisms. In doing so, we assess the level of empirical evidence for these mechanisms and identify the key determinants on which the mechanisms depend. In the discussion, we draw out the implications of our findings for the current practice of SI and highlight opportunities to increase the investment impact of SI.

\section{Conceptual Framework}

The literature review in this article is focused on investor impact, by which we mean the impact that investors have on companies. To explain this concept and show how it relates to the general idea of impact, we begin by developing a conceptual framework that reflects investment impact as a whole. The framework was developed on the basis of established concepts from development finance. However, it was adapted and refined in consultation with practitioners from the SI field. The goal of the framework is to bring conceptual clarity to the idea of investment impact while also reflecting all the components and mechanisms that are deemed relevant by practitioners.

The framework illustrated in Figure 1 reflects three key theoretical assumptions about investment impact. First, impact is defined in terms of the change in social and environmental parameters. Second, investors affect these social and environmental parameters through companies they interact with. Third, there are different mechanisms to achieve investment impact. In the following, we elaborate on these assumptions. The framework is illustrated in Figure 1.

\section{Definitions}

The notion of impact has originally been developed in development finance. The world bank characterizes impact as "(...) causal effects of a program on an outcome of interest" (Gertler 
et al., 2011). There is a rich literature concerned with impact evaluation, mostly with applications to development finance and foreign aid (Bamberger, Rugh, and Mabry, 2012). In this literature, impact is consistently described as having three defining characteristics: (1) it describes a change against a baseline, (2) it relates to a clearly defined parameter, and (3) it implies causality. Applying these characteristics to the case of SI, we define investment impact as "change in a specific social or environmental parameter that is caused by the actions of an investor".

We apply the idea of investment impact to sustainable investing (SI), which we define broadly as "any form of investing that considers environmental, social, and governance (ESG) information as part of the investment process". This definition is the lowest common denominator between the definitions provided by various industry associations (USSIF, EUROSIF, SSF, EFAMA, PRI) and also consistent with the view of the European Parliament (European Parliament, 2013).

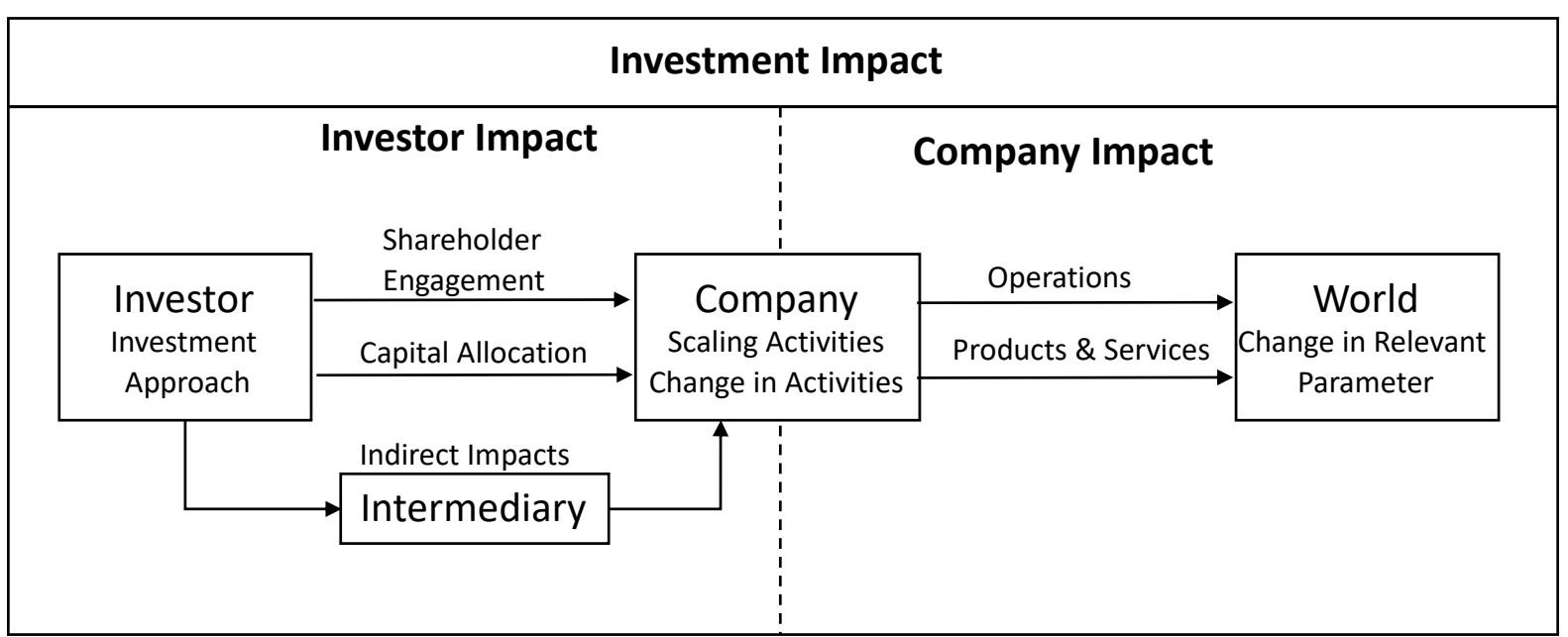

Figure 1: Framework outlining the components and mechanisms of investment impact

\section{The components of investment impact}

Investors affect the real world through the companies they interact with. To reflect this in our framework, we follow Brest \& Born (2013) and split investment impact into two components. Company impact describes the impact of a company on the natural and social environment. Investor impact describes the impact of the investor on the company. Investment impact describes the additional company impact that is due to the activities of an investor. By altering a company's impact, an investor can ultimately influence social or environmental parameters. 
Consider for example a company that manufactures solar panels and achieves a certain amount of carbon emission savings with each solar panel sold. The company's carbon reductions are equal to the number of solar panels sold times the carbon emission savings per panel - this is the company impact. Investors can increase this company impact by helping the company to scale and sell more solar panels. Assume an investor provides capital that enables the company to double its output - this is the investor impact. The overall investment impact in this example is the change that the investor caused in the company's impact on global carbon emissions.

This example makes clear that investor impact and company impact are complementary. When a company has zero company impact, investors cannot have an impact through that company. Likewise, when the investor impact is zero, investors cannot have impact on the company, regardless of how impactful the company's activities may be. Investment impact results only when both investor impact and company impact are present.

\section{The mechanisms for achieving investment impact}

Having clarified the components of investment impact, we turn to the mechanisms behind investment impact. These mechanisms describe how concrete actions by investors and companies are connected and ultimately result in investment impact. Figure 1 shows the identified mechanisms for investor impact and company impact as arrows.

Investor impact can be achieved through three primary impact mechanisms: (1) shareholder engagement impact refers to influencing a company through various communication mechanisms that are open to investors, such as dialogue and shareholder votes. (2) capital allocation impact refers to supporting a company by providing capital - or inhibiting a company by denying the provision of capital. (3) indirect impacts refer to a range of impacts that investors can have on a company through intermediaries that are not direct agents of the investor, for example the company's stakeholders, rating agencies, or other investors.

Through these mechanisms, investors can achieve two different types of changes in company activities. Investors can either cause a company to scale its activities, for example by enabling the company to grow. Alternatively, investors can cause a company to change its activities, for example by influencing the company to adopt a new technology. Whether such a changing or scaling of activities propagates into a real-world impact depends in turn on the impact of these activities - the company impact. 
Company impact can be achieved through two primary mechanisms: (1) directly through the company's operations, i.e., its emissions, its employees, and its resource consumption, and (2) indirectly through the products and services the company provides or purchases.

We acknowledge two limitations of this theoretical framework. First, investors could have impact not only through companies, but also through other investable entities such as countries, or real estate projects. While the impact mechanisms may be similar for these cases, we did not consider these cases explicitly in the literature review, and our conclusions do not necessarily apply. Second, investors may also have impact while bypassing companies or other investable entities altogether, for example through direct engagement with regulators. While this could be an effective measure to have impact, we exclude these types of direct impacts, because actions such as lobbying are not uniquely available to investors.

\section{Methodology}

\section{Scope of the literature review}

The literature review is focused on investor impact, based on three considerations. First, investor impact immediately speaks to the investment activities of sustainable investors and has the most direct implications for sustainable investors. Second, the literature on company impacts is very broad, as company impacts differ enormously for each industry and context. As a result, a thorough review of the literature dealing with company impact would be beyond the scope of this paper. Third, rating agencies are already developing measures for company impact, whereas the concept of investor impact is still widely ignored in practice.

The aim of the literature review is to identify and to bring together the available stock of scientific knowledge on each of the three mechanisms of investor impact. We then analyze these stocks of knowledge in two specific ways. First, we assess the empirical evidence om each of the mechanisms. Second, we identify the key determinants on which the effectiveness of the mechanisms depends.

We conduct a multi-disciplinary literature review, given that the concept of investor impact cuts across disparate literature streams. For each mechanism, we searched academic databases for suitable keywords. We extended this range by also searching for central concepts and keywords contained within identified articles. For example, the concept of "stock price elasticity" was identified as an important theoretical basis for the capital 
allocation impact, directing our search towards a large body of literature dealing with stock price elasticity. This approach ensured that we could identify all articles that are important for the various mechanisms, even if they use different terms to describe the mechanisms, or deal only with essential aspects of the mechanisms in our framework.

Using this approach, we identified a total of 51 relevant articles from a range of different disciplines. The capital allocation impact is dealt with mostly in the financial economics literature, specifically asset pricing and corporate finance. The shareholder engagement impact is dealt with mostly in the corporate governance literature, as well as in management science. The indirect effects are dealt with primarily in business ethics, management science, and sociology.

\section{Literature Review}

\section{Shareholder engagement impact}

Shareholder engagement refers to actions undertaken by shareholders with the intention of changing a company's activities. This includes the right to vote on shareholder proposals during annual general meetings, discussions during informal meetings with management, as well as criticizing corporate practices in news outlets.

The impact of shareholder engagement is relatively straightforward to trace. An investor requests a company to implement a certain change, and the investee either follows through or not. There are four empirical studies that analyze the extent to which companies comply with shareholder engagement requests (Barko, Cremers, and Renneboog, 2017; Dimson, Karakaş, and Li, 2015, 2018; Hoepner et al., 2016).

Dimson et al. (2015), analyzing a dataset of over 2152 shareholder engagement requests between 1999 and 2009, report that 18\% were successful in the sense that the request was implemented by the company. Hoepner et al. (2016) report a success rate of $28 \%$ in a dataset of 682 engagements between 2005 and 2014. Expanding on these results, Barko et al. (2017) report a success rate of $60 \%$ in a sample of 847 engagements between 2005 and 2014. Dimson et al. (2018) report a success rate of $42 \%$ in a sample of 1,671 engagements between 2007 and 2017. Together, these studies provide strong evidence that shareholder engagement is an effective mechanism through which investors can change company activities. 
The success probability of any particular shareholder engagement depends on a host of determinants related to characteristics of the engagement request, the engaged company, the engaging investor, and the specific process of engagement (Goranova and Ryan, 2014). The studies reviewed above highlight three specific determinants that have an important influence on the average rate of success.

The first determinant is the cost of the reform that is associated with complying with the engagement request. A consistent finding of the reviewed studies is that requests in the environmental domain tend to have lower success rates compared to requests in the social domain, and requests in the corporate governance domain have the highest rate of success. Dimson et al. (2015) attribute this to the fact that reforms in the environmental domain are likely to be more costly than in the governance domain. More explicitly, Barko et al. (2017) show that material requests that require some form of reorganization have lower success rates compared to less material requests. Taken together, these findings indicate that the chances of success decrease with the costs of the requested reform.

The second determinant is investor influence. There is evidence that engagement requests are more likely to succeed, when the engaging shareholder holds a larger share of the targeted company (Dimson et al., 2015, 2018). However, investor influence increases not only with the size of the holdings. Dimson et al., (2018) find that a group of engaging investors has more influence when the engagement is spearheaded by an investor that is from the same country as the engaged company, suggesting that linguistic and cultural aspects may play a role as well. Additionally, the chances of success rise when asset managers that are large and internationally renowned are part of the group of engaging investors.

The third determinant is the company's level of ESG experience. The success rate of engagement is higher with companies that have previously complied with engagement requests (Barko et al., 2017; Dimson et al., 2015). Furthermore, companies that have high ESG ratings prior to the engagement are more likely to comply with engagement requests (Barko et al., 2017).

Taken together, these studies provide strong evidence that shareholder engagement exerts a significant influence on companies. The impact of shareholder engagement depends on the cost of the requested reform, on the investor's influence, and on the company's level of ESG experience. 


\section{Capital allocation impact}

The capital allocation impact describes the mechanism where, by allocating capital towards certain sustainable activities, investors increase the amount of these sustainable activities. This mechanism is relevant whenever sustainable investors exclude non-sustainable companies from their portfolios or concentrate their investments in sustainable companies. While the impact of capital allocation may seem intuitive at first sight, it touches upon a rather fundamental question, namely to what extent the decisions of investors influence the course of the real economy.

We were not able to find studies that relate the capital allocation decisions of sustainable investors to corporate investment activities or operational practices. Hence, direct empirical evidence for the capital allocation impact is lacking. However, several strands of literature cover central aspects of capital allocation impact and indicate determinants on which it depends. We structure the review of the literature along the questions: 1) How do investment decisions of sustainable investors influence asset prices? 2) How do changes in asset prices influence companies' activities?

\section{The effect of investment decisions on asset prices}

Two empirical studies, which investigate sustainability preferences in stock markets, come to opposing conclusions regarding the effect on share prices. Hong and Kacperczyk (2009) examine the effect of investors excluding "sin stocks", such as tobacco, alcohol, and gambling from their portfolio. They show that sin stocks have depressed share prices and exhibit outperformance of $2.5 \%$ per year, relative to comparable stocks. This result implies that the moral aversions of investors against sin companies have decreased stock prices of these companies. At the same time, a related study focusing on the effects of divestment in the context of the South Africa boycotts in the 1980s, concludes that the divestments had no discernible effects on asset prices (Teoh, Welch, and Wazzan, 1996).

Recent studies on green bonds, i.e., bonds that are issued to finance projects with environmental benefits, show that the sustainability preferences of investors can influence bond prices. Baker et al. (2018) find that at issue, yields of green bonds are on average $0.06 \%$ below the yields of comparable bonds. They present supporting evidence that the observed differences are caused by non-financial preferences of investors. Similarly, Zerbib (2019) show that sustainability preferences of investors result in a negative yield premium of $0.02 \%$ 
for green bonds. Also, Hachenberg and Schiereck (2018) confirm that green bonds are traded with a negative yield premium.

Taken together, these studies provide evidence that non-financial preferences of investors can affect asset prices. However, the results differ substantially in terms of effect size and do not reveal the determinants of the effect size. To understand these determinants better, we review additional strands of literature within financial economics.

One insightful perspective comes from a theoretical literature that considers the consequences of investor tastes in equilibrium models. Following the efficent market hypothesis, i.e., assuming full rationality and information of all market participants as well as the absence of transaction costs, prices should purely be defined by fundamentals (Fama, 1970). However, several studies show that the existence of non-financial tastes can distort asset prices, in otherwise efficient markets. Based on standard asset pricing models, Fama and French (2007) argue that taste-neutral investors require a premium for balancing out the portfolio choices of investors sharing a particular taste because it forces the neutral investors to deviate from the market portfolio ${ }^{1}$. The impact of sustainable investors' tastes on asset prices has been explicitly modeled in three papers (Beltratti, 2005; Heinkel, Kraus, and Zechner, 2001; Luo and Balvers, 2017).

In accordance with the predictions of Fama and French (2007), all three models show that there are two main determinants on the effect of sustainability tastes on asset prices. First, the total effect size, as well as marginal effect size per additional dollar increases with the fraction of wealth commanded by sustainable investors. Hence the effect of an individual investor's decisions depends on how many others invest according to the same non-financial preferences. Second, the effect is weaker when a company or industry is easily substitutable

${ }^{1}$ Fama and French (2007) also show that disagreement among investors on the probability distributions of future payoffs leads basically to the same price distortions as non-financial tastes of investors. The only difference is that the effects of taste on asset prices are persistent, while the effects of disagreement eventually disappear once the actual development of cash flows is revealed. Hence, the model suggests, for example, that investors, who believe that oil stocks are overpriced given regulatory efforts to limit global warming have the same effect on prices as investors who think oil stocks are ethically unacceptable - until it becomes evident whether oil stocks are indeed overpriced. 
from a portfolio diversification perspective, e.g., if its returns are strongly correlated with business cycles.

Another perspective is provided by empirical studies of stock price elasticity. These studies confirm that non-fundamentally driven changes in demand can influence stock prices. A large set of studies make use of the fact that, due to passive investors, the inclusion or exclusion of companies to or from popular indexes triggers substantial investments in or divestments from these firms. Several studies focus on the S\&P 500 index (e.g., Beneish and Wahley, 1996; Lynch and Mendenhall, 1997; Shleifer, 1986; Wurgler and Zhuravskaya, 2002). Kaul, Mehrotra, and Morck (2000) make use of a rule change of the TSE 300 index; Chang, Hong, and Liskovich (2015) focus on additions to the Russel 2000 index, applying a regression discontinuity approach. These studies find that the observed sudden changes in demand do affect stock prices and that, hence, demand curves for stock slope down. Studies that make use of order-books (Ahern, 2014), announcements of equity issues (Loderer, Cooney, and Van Drunen, 1991) or auction repurchases (Bagwell, 1992) come to similar conclusions as the literature on index inclusions.

There is no consensus on how steep demand curves for stocks are, i.e., how strongly changes in demand affect share prices. A useful measure for the steepness of demand curves in stock markets is the price elasticity of demand. ${ }^{2}$ Highly negative elasticity values indicate little influence of changes in demand, whereas less negative values indicate a stronger influence of demand on prices. The results by Loderer et al. (1991), Kaul et al. (2000), Wurgler and Zhuravskaya (2002) as well as Ahern (2014) indicate elasticities of around -5 to -10. The studies by Bagwell (1992), Chang et al. (2015) and Shleifer (1986) indicate lower elasticities between -1 and -1.5 . While these studies do not agree on how strongly share prices react to changes in demand, price elasticities are higher than, for example, those of food and non-alcoholic beverages, which range from -0.3 to -0.8 (Andreyeva, Long, and Brownell, 2010).

${ }^{2}$ Price elasticity of demand is defined here as $(\% \Delta \mathrm{Q} / \% \Delta \mathrm{P})$, where $\mathrm{Q}$ is the quantity of the demanded good and P it's price. As for stocks, supply curves are vertical, Q can be interpreted as excess demand (Wurgler and Zhuravskaya, 2002). Hence, a price elasticity of -10 implies that a $1 \%$ increase in prices leads to an $10 \%$ decrease in demand. Vice versa, an increase in demand by $10 \%$ would be associated with a $1 \%$ increase in prices. The elasticity of flat demand curve would be negative infinity; and changes in demand would not affect prices. 
Only a few studies investigate demand effects in private markets, such as markets for private equity and venture capital. Gompers and Lerner (2000) show that a doubling of inflows of capital increases the valuation of new investments of venture capital funds between $7 \%$ and $21 \%$. This would correspond to an elasticity of -5 to -14 . Diller and Kaserer (2009) confirm that demand effects influence private equity funds' return.

Both Wurgler and Zhuravskaya (2002) and Ahern (2014) find that stocks with low substitutability show a lower price elasticity. This implies that prices for stocks that are not easily replaceable with similar assets react stronger to changes in demand. This is in line with the findings derived from equilibrium models, as reported above.

\section{The effect of changes in asset prices on corporate activities}

Even if the preferences of sustainable investors succeed to alter asset prices, this may not necessarily translate into changes in corporate activities. So far, there is no empirical evidence that the capital allocation decisions of sustainable investors have affected corporate activities. However, the reviewed literature identifies two general channels how companies can be affected by changing asset prices: Changes in costs of capital can influence how fast companies are able to scale their activities, while managerial incentives can cause companies to change their activities.

The first channel operates via the cost of capital. As stock markets define the cost of equity capital, they may affect corporate investment activity, as postulated by Fischer and Merton, (1984). An increase in stock market valuation caused by investor's taste may make it more attractive for a company to raise equity capital to implement investment options. Vice versa, depressed share prices may force companies to reduce investment opportunities. However, as pointed out by Beltratti (2005), companies shunned on stock markets may shift towards debt financing if sustainability preferences are not shared by debt investors as well. Accordingly, Hong and Kacperczyk (2009) show that sin companies seem to rely more on debt financing, possibly evading the effect.

Empirical work shows that reduced costs of capital do not necessarily translate in increased corporate investment and growth. Baker et al. (2003) show that the sensitivity of investment activity to non-fundamental movements in stock prices is only high for firms that depend on external capital. According to Kaplan and Zingales (1997) many publicly traded companies do not depend on external capital. Especially large, established companies often have sufficiently large cash flows to cover investments. In contrast, a series of empirical 
studies show that small firms, young firms, firms operating in less mature financial markets with weak institutions as well as firms with less tangible assets are more likely to be restricted in their investment activity by the cost of external financing (Almeida and Campello, 2007; Beck et al., 2006; Beck, Demirguc-Kunt, and Maksimovic, 2008; Bloom et al., 2010; Rajan and Zingales, 1996). Especially in developing countries, many small and medium-sized companies are completely lacking access to external financing (Beck, 2007; Beck and Demirguc-Kunt, 2006). The finding that many small firms are restricted by the cost of capital or even access to capital is consistent with the finding that most small companies use retained earnings, insider finance, and trade credit to finance their investments (Berger and Udell, 1998; Carpenter and Petersen, 2002). Financing constraints seem to have a particularly strong inhibiting effect on entrepreneurial activities. Evans and Jovanovic (1989), as well as Holtz-Eakin, Joulfaian, and Rosen (1994) show that wealthy individuals are much more likely to become successful entrepreneurs. Hence, the likelihood that changes in asset prices influence the growth of a company increases with the degree to which a company is restricted by external financing conditions.

The second channel operates via managerial incentives. Edmans et al. (2012) argue that when managerial incentives are tied to stock market value, managers will be sensitive to shifts in the share price of their corporation - regardless of the reliance on external financing. Thus, if SI leads to a shift in asset prices, conforming to the expectations of sustainable investors can be profitable (Gollier and Pouget, 2014). The key criterion for this to hold is that the cost of reform is lower than the expected gain in market valuation. Based on their equilibrium model, Heinkel et al. (2001) provide a numerical example in which at least 20\% of the market need to apply a common screen, to create the incentives to implement reforms that cost a company $5 \%$ of its annual cash flow.

\section{Summary}

While there is evidence that the preferences of sustainable investors can influence asset prices, so far there is no direct evidence that these changes have altered corporate activities. However, based on the reviewed literature we can identify a number of factors that make capital allocation impact more or less likely.

The effect of investor decisions on asset prices increases with the market share of investors with common non-financial preferences as well as the degree to which the portfolios of these investors deviate from the market portfolio. It decreases with the 
substitutability of affected assets. Considering these factors, the outperformance of sin stocks reported by Hong and Kacperczyk (2009) may represent an upper bound for the effect sustainable investors can have on stock prices ${ }^{3}$.

The cost of reform determines whether changes in asset prices provide managerial incentives to change corporate practices or whether those changes mainly affect the company's growth by altering its cost of capital. The likelihood of whether a company's growth is influenced by changes in the cost of capital decreases with the size, age, the tangibility of its assets, as well as the maturity of financial markets it is operating in. For companies that do not have access to capital markets, such as many small and medium-sized firms in developing countries, the questions of capital allocation impact is reduced to whether a company has viable investment options that could be realized with external capital.

Whereas the reviewed studies agree on the direction in which the identified factors influence the capital allocation effect, the results differ substantially regarding the magnitude of influence. Thus, while we can say that the capital allocation impact of a given investment decision depends on the identified determinants, the literature to date does not allow a quantification of the capital allocation impact.

\section{Indirect Impacts}

Next to the impacts of shareholder engagement and capital allocation, investors may also influence companies indirectly through intermediaries. We identified four different indirect impact mechanisms: stigmatization impact, endorsement impact, benchmarking impact, and demonstration impact.

\section{Stigmatization impact}

Investors can stigmatize a company by divesting the company's assets or categorically excluding it from their portfolio. Apart from a capital allocation impact that this might have,

${ }^{3}$ The aversion against sin stocks is arguably one of the most widely shared nonfinancial preferences among investors. At the same time the returns of sin stocks are largely independent of business cycles, and thus sin stocks are not easily substitutable in a diversified portfolio. 
the action can also impact other relevant stakeholders of the company. For example, people might be deterred from working at a company that is excluded by investors. Literature on this stigmatization impact, however, is thin. In a detailed assessment of the carbon divestment movement, Ansar, Caldecott, and Tilbury (2013) postulate that one of its most important impacts might be the stigmatization of the fossil fuel industry. For the anti-apartheid divestment campaign, there is anecdotal evidence that it helped to lift the issue of Apartheit on the political agenda. Desmond Tutu, South African archbishop and an important figure in the struggle against the Apartheid regime commented that the disinvestment campaign in the US added punch to their political struggle (Knight, 1990). However, we were not able to find studies that analyze to what extent exclusion decisions by sustainable investors have lead to stigmatization.

\section{Endorsement impact}

Investors can endorse companies for their social or environmental performance by including them in their portfolio or sustainability index. Such an endorsement may help to increase the visibility and reputation of a company, indirectly helping the company to gain customers or motivate employees. We were not able to identify studies that analyze to what extent company reputation was improved as a consequence of investor endorsement. There are two studies, however, that investigate whether companies that were included in a sustainability index decided subsequently to communicate this inclusion to stakeholders (Carlos and Lewis, 2018; Searcy and Elkhawas, 2012). The fact that companies communicate index inclusion suggests that such an inclusion helps to improve reputation, yet the studies do not investigate the magnitude of this impact. They show, however, that nearly half of the companies that were included in the Dow Jones Sustainability Index chose not to communicate their inclusion publicly. Carlos and Lewis (2018) find that companies are more likely to remain silent about their index membership, when they have a strong reputation for ESG performance already. Thus, one important determinant of the endorsement effect seems to be a company's prior ESG reputation.

\section{Benchmarking impact}

SI is feeding a growing industry of ESG rating agencies. These rating agencies develop standards, create ESG benchmarks, and request increasing amounts of data from companies. The growth of this industry is likely to encourage companies to report on their practices, in order to satisfy the increasing data demands. Measuring and reporting may then also induce 
companies to improve their performance, for example because companies are benchmarked against peers.

The literature provides no direct evidence that investors have impact via their support of ESG rating agencies. However, a number of studies have investigated the impact of standards and ratings on social and environmental performance. Regarding standards, there is one study that concludes that the introduction of the voluntary ISO 14000 standard for environmental management has led firms to improve their environmental outcomes (Melnyk, Sroufe, and Calantone, 2003). Another study, however, concludes the adoption of this standard had no discernible effect on environmental outcomes (Hertin et al., 2008).

Studying ESG benchmarks specifically, Chatterji and Toffel (2010) provide evidence that companies improve environmental performance in response to receiving a low rank in an environmental benchmark. They find this especially to be the case when the cost of reform is low, and when the industry operates in a highly regulated industry. A problem with this effect, however, is that there are remarkable differences between ESG benchmarks compiled by different agencies (Chatterji et al., 2016). Due to these differences, the authors conclude that "SRI ratings will have a limited impact on driving rated firms toward any particular shared behaviors". One important determinant of the effectiveness of the benchmarking impact is thus the consistency of ESG benchmarks.

\section{Demonstration impact}

One investor engaging in SI may encourage other investors to do the same so that the original investor has an indirect effect through those additional investors. While exactly this "mainstreaming" of SI was a key goal of industry associations such as the Principles for Responsible Investing (PRI), we found no research documenting such a demonstration effect in the context of SI.

\section{Summary}

In summary, there is no direct empirical evidence for any of the considered indirect impacts. This is not surprising, given that indirect impacts are difficult to measure. By definition, they involve an additional intermediary, so that both the investor's impact on that intermediary as well as the impact of the intermediary on the company need to be considered. As a result, indirect impacts could be relevant, but they are inherently uncertain and hard to measure.

We find no concrete evidence for the stigmatization impact and the demonstration impact. Parts of the endorsement impact and the benchmarking impact have been studied, and 
these studies revealed two determinants. Endorsement impacts are likely to be more relevant for companies with low ESG reputations. Benchmarking impacts are likely to be more relevant, when different ESG benchmarks are consistent.

\section{Discussion}

Academic literature has shown enormous interest in SI, most prominently under the theme of 'doing good by doing well'. However, this literature has almost exclusively focused on the 'doing well' part, and hardly investigated the 'doing good' part so far. This is problematic because the central motivation to study the financial performance of SI is the assumption that it has a positive impact. If SI did not have at least some social and environmental benefits, its financial performance would be quite irrelevant from a scholarly point of view. The assumption that SI has positive impact, however, should not be taken for granted - it needs to be examined.

This article begins to examine the impact of SI and makes three central contributions in doing so. First, the article provides a conceptual basis to evaluate the social and environmental impacts of SI going forward. Second, the article provides a comparison of different impact mechanisms based on available literature. Third, the article identifies critical research gaps that need to be closed in order to work towards a quantification of investment impact. Furthermore, the results of this article have important implications for practitioners, in particular for data providers and fund managers. In the following, we discuss these points in detail.

\section{A basis for the evaluation of investment impact}

As a first contribution, this article provides a basis for evaluating investment impact going forward. It provides a definition and a framework of investment impact, specifying what is meant with 'doing good' in the context of SI. The definition is parsimonious and flexible. And yet, it introduces key requirements that are suited to constrain the excessive use of the term 'impact', notably that merely analyzing company impact does not provide a measure of investment impact.

In addition to the definition, this article puts forward a framework that clarifies the key steps and mechanisms that comprise investment impact. This framework may serve to structure the discussion about investment impact beyond this article. The article has shown that the concept of investment impact cuts across a wide variety of disciplines. This means 
that in order to fully understand investment impacts, financial economists, management scholars, sociologists, and ecologists will need to collaborate and complement each other. The framework could support this multi-disciplinary effort by highlighting where different disciplines can contribute to the overall understanding of investment impact.

\section{Assessment and comparison of investor impact mechanisms}

As a second contribution, the article provides a comprehensive assessment and comparison of the identified investor impact mechanisms, based on the current academic literature. In particular, the article compares the level of empirical evidence supporting the mechanisms and identifies the key determinants on which the different impact mechanisms depend. These key results are summarized in Table 1.

Shareholder engagement emerges from the literature review as a relatively certain way to achieve impact. Several studies provide direct evidence that investors have impact on company activities through shareholder engagement. The studies also identify three key determinants. The investor impact of shareholder engagement increases with the influence of the engaging investor and the ESG experience of the engaged company. The investor impact decreases with the cost of the requested reforms. Shareholder engagement is therefore suited as a mechanism that reliably results in impacts, which investors could quantify and communicate.

The capital allocation impact emerges from the literature review as a somewhat uncertain way to achieve impact since the literature provides no direct evidence that SI influences company activities through capital allocation. However, its individual parts have been analyzed in detail and are relatively well understood. As a result, there are clear indications regarding the determinants on which capital allocation impacts depend. The capital allocation impact increases with the share of sustainable investors having the same sustainability preferences, the extent to which these preferences results in deviations from the market portfolio, and the company's dependency on external capital. The capital allocation impact diminishes with the substitutability of the assets that are under- or overweighted as well as with the cost of reform. Given the lack of direct quantitative evidence, the capital allocation effect could range between substantial and negligible, depending on these determinants. 
Table 1: Comparison of impact mechanisms

\begin{tabular}{|c|c|c|}
\hline Mechanism & $\begin{array}{c}\text { Level of empirical } \\
\text { evidence }\end{array}$ & Key Determinants \\
\hline \multicolumn{3}{|l|}{ Direct Impacts } \\
\hline $\begin{array}{l}\text { Shareholder } \\
\text { Engagement } \\
\text { Impact }\end{array}$ & $\begin{array}{l}\text { Direct evidence } \\
\text { Entire mechanism } \\
\text { has been analyzed }\end{array}$ & $\begin{array}{l}\text { 1. Investor influence }(+) \\
\text { 2. Company's level of ESG experience }(+) \\
\text { 3. Cost of requested reform }(-)\end{array}$ \\
\hline $\begin{array}{l}\text { Capital } \\
\text { Allocation } \\
\text { Impact }\end{array}$ & $\begin{array}{l}\text { Indirect evidence } \\
\text { Key parts of the } \\
\text { mechanism have } \\
\text { been analyzed } \\
\text { separately }\end{array}$ & $\begin{array}{l}\text { 1. Market share of SI investors }(+) \\
\text { 2. Deviation from market portfolio }(+) \\
\text { 3. Substitutability }(-) \\
\text { 4. Cost of reform }(-) \\
\text { 5. Dependence on external capital }(+)\end{array}$ \\
\hline \multicolumn{3}{|l|}{ Indirect Impacts } \\
\hline $\begin{array}{l}\text { Stigmatization } \\
\text { Impact }\end{array}$ & No evidence & \\
\hline $\begin{array}{l}\text { Endorsement } \\
\text { Impact }\end{array}$ & $\begin{array}{l}\text { Partial evidence } \\
\text { Some parts of the } \\
\text { mechanism have } \\
\text { been analyzed in } \\
\text { isolation }\end{array}$ & 1. ESG reputation prior to endorsement (-) \\
\hline $\begin{array}{l}\text { Benchmarking } \\
\text { Impact }\end{array}$ & $\begin{array}{l}\text { Partial evidence } \\
\text { Some parts of the } \\
\text { mechanism have } \\
\text { been analyzed in } \\
\text { isolation }\end{array}$ & 1. Consistency of ESG benchmarks $(+)$ \\
\hline $\begin{array}{l}\text { Demonstration } \\
\text { Impact }\end{array}$ & No evidence & \\
\hline
\end{tabular}

Finally, indirect impacts emerge as very uncertain from the literature review. By definition, indirect impacts are routed through an additional intermediary, which prolongs the causal chain between an investors action and its effect on a company. While there is anecdotal evidence for indirect impacts, none of these impacts has been analyzed comprehensively, in the sense that the action of an investor was related to company activities. There is no empirical evidence for the stigmatization and the demonstration impact. There is 
partial evidence for the endorsement and the benchmarking impact. Endorsements are likely to be more valuable when the endorsed company has a low ESG reputation. Benchmarking is likely to be more effective when different ESG benchmarks are consistent, i.e. they identify the same laggards and leaders. It's important to note that the evidence on these indirect impacts is only partial, there may be additional determinants that have not been identified yet.

\section{Research gaps}

As a third contribution, this article identifies critical research gaps that inhibit SI funds from monitoring and increasing their investment impact. Regarding shareholder engagement, an important practical research question is how to report the impact of engagement activities. A handful of empirical studies have shown that it is feasible to quantify impact. A next step could be to formulate reporting guidelines to ensure that these impacts are comparable across different cases and regions and can be reported in a standardized and understandable format.

Regarding capital allocation impact, there is currently no empirical study that relates capital allocation decisions by sustainable investors to corporate investment decisions. Hong \& Kacperczyk (2009) point out that while their study demonstrates an effect on the share prices of tobacco companies, it does not investigate the effects on the activities of tobacco companies. Studies that relate SI activities not only to asset prices but also investigate the response of affected companies in terms of management and investment decisions would advance the understanding of investor impact decisively because it would provide direct evidence of investor impact through capital allocation.

Regarding indirect impact, there is a need for studies that investigate the entire causal chain of indirect impacts. Existing studies document indirect impacts only partially. Due to their complexity, indirect impacts are suited for qualitative research methods. Comprehensive case studies that carefully trace indirect impact mechanisms could provide important guidance when indirect impacts matter and in which way they could be pursued most fruitfully.

\section{Implications}

Our results have important practical implications for the SI industry. First, it suggests that data providers have an important role in developing impact measures that reflect company impact and investment impact. Second, the article points out concrete ways in which investors and fund managers could evolve the current practice of SI towards greater investment impact. 
The key data providers of the SI industry are the so-called environmental, social, and governance (ESG) rating agencies. ESG rating agencies, such as MSCI, Sustainalytics, or ISS have developed comprehensive datasets that reflect companies' sustainability performance across a wide spectrum. Portfolios of SI funds tend to overweight companies with good ESG ratings and underweight companies with poor ESG ratings. SI funds are also benchmarked regarding their portfolio-weighted ESG ratings, such as the Morning Star Sustainability rating. As a result, ESG ratings play an important role in guiding SI decisions.

Recently, several ESG data providers have begun to develop impact metrics that relate company performance to wider outcomes such as the United Nations' Sustainable Development Goals (see e.g. Vörösmarty et al., 2018). These efforts are a very important step to guide SI towards greater impact. And yet, these metrics are incomplete as long as they are focused only on company impact and do not reflect investor impact.

At the portfolio level, metrics that exclusively consider company impacts result in misleading assessments of a fund's overall investment impact. Such metrics do not distinguish between funds that have a major investor impact, and funds that have negligible investor impact. As a result, a fund that successfully induces emission intensive companies to improve their practices may appear to have less impact than a fund that simply has exposure to companies that already have these practices in place. As a result, metrics based only on company impact cannot indicate a fund's overall investment impact.

Therefore, ESG data providers should complement their assessments of company impacts with an assessment of investor impact. This article provides an initial overview of the relevant mechanisms and determinants that would be relevant for such an investor impact assessment. While estimating investor impact will require investment in novel methodologies, developing these methodologies may be attractive due to their scalability: company impacts require different methodologies for each industry, investor impacts apply generally to any investment.

For investors and fund managers, the article points to a number of concrete ways in which the impact of current approaches to SI could be increased. While SI is a diverse industry and any investment has some impact in principle, the bulk of SI assets is currently invested in ways that promise relatively modest and perhaps even negligible investment impact. In the US, only $10 \%$ of SI assets are associated with shareholder engagement (USSIF, 2018), meaning that the most reliable impact mechanism is only rarely used. Also, the capital 
allocation impact may not be very relevant in practice. Frequently, SI funds focus on the stocks and bonds of large established companies that are least sensitive to capital allocation impacts. In addition, while the overall market share of SI assets is growing, it is diluted by disagreement about which companies are the most and least sustainable (Chatterji et al., 2016). Thus, the current practice of SI offers a number of ways to increase impact.

First, fund managers could expand shareholder engagement activities. A number of studies identify shareholder engagement as a reliable mechanism to achieve investment impact. Shareholder engagement is also quite flexible, as it can be combined with most existing investment approaches. SI funds and service providers already practicing shareholder engagement could exploit the fact that the impacts of shareholder engagement are measurable and communicate their actual investment impacts more prominently.

Second, investors could enhance capital allocation impacts by considering the determinants identified in this article. Regarding market share, sustainable investors could coordinate and focus on a few, widely shared priority issues and make sure that they are consistently assessed. The most promising priority issues would be practices that have major company impact, but which can be implemented by companies at low or even negative costs. Finally, SI funds might focus on companies and markets where external capital is a limiting factor, such as small-cap growth stocks in emerging markets.

Third, investors who are convinced that they can have indirect impacts could attempt to demonstrate these effects. While indirect effects have currently little scientific support, SI funds could provide examples and proxies that make these effects more tangible. For instance, investors could measure media attention in response to an exclusion announcement. Fund managers who launch an innovative product could track the uptake of their innovation by others to support their demonstration impact. Data providers, finally, could also attempt to show how their work with companies leads to operational improvements, and share these findings with the investors that pay for their services.

Finally, the SI industry could profit from adopting a common definition of investment impact. This article provides a succinct definition, along with a framework that might aid the practitioner debate around impact. The basic idea that investment impact refers to the contribution that investors make towards a company's real-world impact is straightforward. A clear understanding of investment impact would help to distinguish it from other objectives 
associated with SI, such as risk management or value alignment, and provide essential support to SI funds that indeed achieve investment impact.

\section{Limitations}

We acknowledge three limitations. First, the presented recommendations are based on qualitative observations. While the literature review allowed us to identify mechanisms and determinants, we cannot judge the relative importance of some determinants in comparison to others. Such a quantitative comparison would, however, be an interesting future research project.

Second, the academic literature is biased towards publicly listed corporations and stock markets, due to data availability. Accordingly, also this literature review is somewhat biased towards public stock markets. There are potentially further relevant impact mechanisms in specific financial markets, such as corporate debt, private equity, bank lending, and real estate, which are not reflected in this article.

Third, this review article was limited to investor impact, even though company impact is an equally important component of investment impact. It is challenging to review company impacts, given that company impacts are very industry specific. Nevertheless, a thorough review of company impacts would provide a helpful complement to this article.

\section{Conclusion}

Increasingly, SI is thought of as a tool to achieve environmental or social outcomes, such as the United Nation's sustainable development goals. However, to date there is very little research that investigates the impacts of SI, creating a wide research gap around a rather fundamental issue. This article begins to close this research gap by way of a multidisciplinary literature review. It makes three specific contributions.

First, the article provides a definition of investment impact, along with a framework that identifies the central components and mechanisms of investment impact. The framework highlights that investor impact and company impact are separate but complementary components of investment impact. For mechanisms of investor impact, the framework distinguishes shareholder engagement impact, capital allocation impact, and indirect impacts.

Second, the article conducts a systematic literature review of the investor impact mechanisms. It brings together the available evidence for three impact mechanisms and identifies for each mechanism the key determinants that increase or decrease investor impact. 
Shareholder engagement emerges as the only impact mechanism that is directly supported in the literature. There is no direct evidence for the capital allocation impact, but the literature clearly identifies the determinants on which it depends. Indirect effects have little support in the literature so far.

Third, the article derives key implications for data providers and SI funds. Data providers could play an important role in stimulating the impact of SI by providing measures that reflect both company and investor impact. Investors who want to have impact could expand shareholder engagement activities and increase their capital allocation impact, for example by screening for specific corporate practices with low reform costs in unison with a large coalition of investors, or by focusing on small and medium-sized companies that have positive company impact but lack access to external capital.

\section{References}

Ahern KR. 2014. Do Common Stocks Have Perfect Substitutes? Product Market Competition and the Elasticity of Demand for Stocks. Review of Economics and Statistics 96(4): 756-766.

Almeida H, Campello M. 2007. Financial Constraints, Asset Tangibility, and Corporate Investment. The Review of Financial Studies 20(5): 1429-1460.

Andreyeva T, Long MW, Brownell KD. 2010. The Impact of Food Prices on Consumption: A Systematic Review of Research on the Price Elasticity of Demand for Food. American Journal of Public Health 100(2): 216-222.

Ansar A, Caldecott B, Tilbury J. 2013. Stranded assets and the fossil fuel divestment campaign : what does divestment mean for the valuation of fossil fuel assets?

Bagwell LS. 1992. Dutch Auction Repurchases: An Analysis of Shareholder Heterogeneity. The Journal of Finance 47(1): 71-105.

Baker M, Bergstresser D, Serafeim G, Wurgler J. 2018. Financing the Response to Climate Change: The Pricing and Ownership of U.S. Green Bonds. Working Paper, National Bureau of Economic Research. Available at: http://www.nber.org/papers/w25194.

Baker MP, Stein JC, Wurgler JA. 2003. When Does the Market Matter? Stock Prices and the Investment of Equity-Dependent Firms. The Quarterly Journal of Economics (August): 969-1005. 
Bamberger M, Rugh J, Mabry L. 2012. Real World Evaluation. Sage: Thousand Oaks, CA.

Barko T, Cremers M, Renneboog L. 2017. Shareholder Engagement on Environmental, Social, and Governance Performance (August). Available at: https://papers.ssrn.com/sol3/papers.cfm?abstract_id=2977219.

Beck T. 2007. Financing Constraints of SMEs in Developing Countries: Evidence, Determinants and Solutions. In Financing innovation-oriented businesses to promote entrepreneurship: 36.

Beck T, Demirguc-Kunt A. 2006. Small and medium-size enterprises: Access to finance as a growth constraint. Journal of Banking \& Finance 30(11): 2931-2943.

Beck T, Demirgüç-Kunt A, Laeven L, Maksimovic V. 2006. The determinants of financing obstacles. Journal of International Money and Finance 25(6): 932-952.

Beck T, Demirguc-Kunt A, Maksimovic V. 2008. Financing patterns around the world: Are small firms different? Journal of Financial Economics 89(3): 467-487.

Beltratti A. 2005. Capital market equilibrium with externalities, production and heterogeneous agents. Journal of Banking \& Finance 29(12): 3061-3073.

Beneish MD, Wahley RE. 1996. An Anatomy of the "S\&P Game ": The Effects of Changing the Rules. The Journal of Finance 39(5): 1909-1930.

Berger AN, Udell GF. 1998. The economics of small business finance: The roles of private equity and debt markets in the financial growth cycle. Journal of Banking \& Finance 22(6): 613-673.

Betti G, Consolandi C, Eccles RG. 2018. Supporting Sustainable Development Goals Is Easier Than You Might Think. Sustainability 10(7).

Bloom N, Mahajan A, McKenzie D, Roberts J. 2010. Why Do Firms in Developing Countries Have Low Productivity? American Economic Review 100(2): 619-623.

Brest P, Born K. 2013. Unpacking the Impact in Impact Investing. Stanford Social Innovation Review 11(4): 22-31.

Carlos WC, Lewis BW. 2018. Strategic Silence: Withholding Certification Status as a Hypocrisy Avoidance Tactic. Administrative Science Quarterly 63(1): 130-169.

Carpenter RE, Petersen BC. 2002. Is the Growth of Small Firms Constrained by Internal Finance? Review of Economics and Statistics 84(2): 298-309. 
Chang Y-C, Hong H, Liskovich I. 2015. Regression Discontinuity and the Price Effects of Stock Market Indexing. Review of Financial Studies 28(1): 212-246.

Chatterji AK, Durand R, Levine DI, Touboul S. 2016. Do ratings of firms converge?

Implications for managers, investors and strategy researchers. Strategic Management Journal 37(8): 1597-1614.

Chatterji AK, Toffel MW. 2010. How firms respond to being rated. Strategic Management Journal. Wiley Online Library 31(9): 917-945.

Diller C, Kaserer C. 2009. What Drives Private Equity Returns?- Fund Inflows, Skilled GPs, and/or Risk?*. European Financial Management 15(3): 643-675.

Dimson E, Karakaş O, Li X. 2015. Active Ownership. Review of Financial Studies 28(12): $3225-3268$.

Dimson E, Karakaş O, Li X. 2018. Coordinated Engagements. Available at: https://papers.ssrn.com/abstract=3209072.

Edmans A, Goldstein I, Jiang W. 2012. The Real Effects of Financial Markets: The Impact of Prices on Takeovers. The Journal of Finance 67(3): 933-971.

European Parliament. 2013. Corporate social responsibility: accountable, transparent and responsible business behaviour and sustainable growth - European Parliament resolution of 6 February 2013 on corporate social responsibility: accountable, transparent and responsible business b. P7_TA. Available at: http://www.europarl.europa.eu/sides/getDoc.do?pubRef=-//EP//TEXT+TA+P7-TA2013-0049+0+DOC+XML+V0//EN.

Evans DS, Jovanovic B. 1989. An Estimated Model of Entrepreneurial Choice under Liquidity Constraints. Journal of Political Economy 97(4): 808-827.

Fama EF. 1970. Efficient Capital Markets: A Review of Theory and Empirical Work. The Journal of Finance 25(2): 383-417.

Fama EF, French KR. 2007. Disagreement, tastes, and asset prices. Journal of Financial Economics 83(3): 667-689.

Fischer S, Merton RC. 1984. Macroeconomics and Finance: The Role of the Stock Market. Working Paper, National Bureau of Economic Research. Available at: http://www.nber.org/papers/w1291. 
Friede G, Busch T, Bassen A. 2015. ESG and Financial Performance: Aggregated Evidence from more than 2000 Empirical Studies. Journal of Sustainable Finance \& Investment (Forthcoming) 5(4): 210-233.

Gertler PJ, Martinez S, Premand P, Rawlings LB, Vermeersch CMJ. 2011. Impact Evaluation in Practice. The World Bank.

Gollier C, Pouget S. 2014. The "Washing Machine”: Investment Strategies and Corporate Behavior with Socially Responsible Investors. Toulouse School of Economics: 26.

Gompers P, Lerner J. 2000. Money chasing deals? The impact of fund inflows on private equity valuation. Journal of Financial Economics 55(2): 281-325.

Goranova M, Ryan LV. 2014. Shareholder Activism: A Multidisciplinary Review. Journal of Management 40(5): 1230-1268.

GSIA. 2016. 2016 Global Sustainable Investment Review.

Hachenberg B, Schiereck D. 2018. Are green bonds priced differently from conventional bonds? Journal of Asset Management 19(6): 371-383.

Hartzmark SM, Sussman AB. 2017. Do Investors Value Sustainability? A Natural Experiment Examining Ranking and Fund Flows. SSRN Electronic Journal. Available at: https://www.ssrn.com/abstract=3016092.

Heinkel R, Kraus A, Zechner J. 2001. The effect of green investment on corporate behavior. Journal of Financial and Quantitative Analysis 36(4): 431-449.

Hertin J, Berkhout F, Wagner M, Tyteca D. 2008. Are EMS environmentally effective? The link between environmental management systems and environmental performance in European companies. Journal of Environmental Planning and Management 51(2): $259-283$.

Hoepner A, Starks LT, Sautner Z, Zhou X, Oikonomou I. 2016. ESG shareholder engagement and downside risk. Available at: https://ssrn.com/abstract=2874252.

Holtz-Eakin D, Joulfaian D, Rosen HS. 1994. Sticking it Out: Entrepreneurial Survival and Liquidity Constraints. Journal of Political Economy 102(1): 53-75.

Hong H, Kacperczyk M. 2009. The price of sin: The effects of social norms on markets. Journal of Financial Economics. Elsevier 93(1): 15-36. 
IPCC. 2014. Climate Change 2014: Synthesis Report. Contribution of Working Groups I, II and III to the Fifth Assessment Report of the Intergovernmental Panel on Climate Change: 151.

Kaplan SN, Zingales L. 1997. Do Investment-Cash Flow Sensitivities Provide Useful Measures of Financing Constraints? The Quarterly Journal of Economics 112(1): $169-215$.

Kaul A, Mehrotra V, Morck R. 2000. Demand Curves for Stocks Do Slope Down: New Evidence from an Index Weights Adjustment. The Journal of Finance 55(2): 893912.

Knight R. 1990. Sanctions, Disinvestment, and US Corporations in South Africa. In Sanctioning Apartheid. Africa World Press: 67-89.

Koellner T, Suh S, Weber O, Moser C, Scholz RW. 2008. Environmental Impacts of Conventional and Sustainable Investment Funds Compared Using Input-Output LifeCycle Assessment. Journal of Industrial Ecology 11(3): 41-60.

Loderer C, Cooney JW, Van Drunen LD. 1991. The Price Elasticity of Demand for Common Stock. The Journal of Finance 46(2): 621-651.

Luo HA, Balvers RJ. 2017. Social Screens and Systematic Investor Boycott Risk. Journal of Financial and Quantitative Analysis 52(01): 365-399.

Lynch AW, Mendenhall RR. 1997. New Evidence on Stock Price Effects Associated with Changes in the S\&P 500 Index. The Journal of Business 70(3): 351-383.

Melnyk SA, Sroufe RP, Calantone R. 2003. Assessing the impact of environmental management systems on corporate and environmental performance. Journal of Operations Management 21(3): 329-351.

Molthan P. 2003. Introduction. In Ethical and Socially Responsible Investment - A reference guide for Researchers, Broadhurst D, Watson J, Marshall J (eds). Saur Verlag: Munich.

Rajan R, Zingales L. 1996. Financial Dependence and Growth. National Bureau of Economic Research, Cambridge, MA. Available at: http://www.nber.org/papers/w5758.pdf. 
Richardson BJ. 2009. Keeping Ethical Investment Ethical: Regulatory Issues for Investing for Sustainability. Journal of Business Ethics 87(4): 555-572.

Riedl A, Smeets P. 2017. Why do investors hold socially responsible mutual funds? Journal of Finance 72(6): 2505-2550.

Rivoli P. 2003. Making a Difference or Making a Statement? Business Ethics Quarterly 13(3): 271-287.

Searcy C, Elkhawas D. 2012. Corporate sustainability ratings: an investigation into how corporations use the Dow Jones Sustainability Index. Journal of Cleaner Production 35: 79-92.

Shleifer A. 1986. Do Demand Curves for Stocks Slope Down? The Journal of Finance 41(3): $579-590$.

Singer P. 2015. The Most Good You Can Do: How Effective Altruism Is Changing Ideas About Living Ethically. Yale University Press: New Haven, Connecticut.

USSIF. 2018. Report on US Sustainable, Responsible and Impact Investing Trends. Available at: https://www.ussif.org/files/Trends/Trends\%202018\%20executive\%20summary\%20FI NAL.pdf.

Vörösmarty CJ et al. 2018. Scientifically assess impacts of sustainable investments. Science 359(6375): 523-525.

Wurgler J, Zhuravskaya E. 2002. Does Arbitrage Flatten Demand Curves for Stocks? The Journal of Business 75(4): 583-608.

Zerbib OD. 2019. The effect of pro-environmental preferences on bond prices: Evidence from green bonds. Journal of Banking \& Finance 98: 39-60. 